\title{
PROTECTED AREAS IN PAKISTAN: MANAGEMENT AND ISSUES
}

\author{
ZAFAR IQBAL KHAN \\ Ministry of Science \& Technology, Islamabad, Pakistan
}

Proceedings of the South and Central Asian MAB Meeting of Experts on Environmental Conservation, Management and Research, Hikkaduwa, Sri Lanka 15-18 October 2002

Pakistan stretches from the Arabian Sea to the high mountains of Central Asia, and covers an area of $803,944 \mathrm{~km}^{2}$. It lies approximately between $24^{\circ}$ and $37^{\circ}$ north latitude, and between $61^{\circ}$ and $78^{\circ}$ east longitude. It neighbours Iran to the west, Afghanistan to the north, China to the northeast, and India to the east and southeast. There is a $1,000 \mathrm{~km}$ long coastline along the Arabian Sea.

Its biodiversity is composed of a blend of Palaearctic and Indomalayan elements, with some groups also containing forms from the Ethiopian region. Indomalayan forms are found in the east of the country, in the Indus Basin, and Palaearctic forms in the mountains of the north and west. The Palaearctic species contain a mixture of those common to a large part of Eurasia, along with those with affinities to the Middle East, West Asia (Afghanistan and Iran), Central Asia, and Tibet. The rate of endemism is relatively low ( $5 \%$ for plants, $4 \%$ for mammals, $0 \%$ for birds, $10 \%$ for reptiles, and $11 \%$ for fish), but the blending of elements from different origins has ensured a diverse and unique mix of flora and fauna. Since a lot of primary field research still needs to be done, these statistics are likely to under represent the actual biodiversity of Pakistan.

The ecological trend of greatest concern in Pakistan today is the continuing loss, fragmentation and degradation of natural and modified habitats: the forest area, already greatly reduced and fragmented, is suffering further loss and degradation; most rangelands are suffering further degradation; and many freshwater and marine ecosystems have already been lost or are threatened with further destruction. Also of great concern in Pakistan today is the continuing decline of many native species of animals and plants; some species are already extinct, many are internationally threatened, and still more are of national concern. The degradation of agro-ecosystems and the accelerating loss of domesticated genetic diversity are also of grave concerns to Pakistan.

The conservation of biodiversity is fundamental to achieving sustainable development. It provides flexibility and options for our current and future use of natural resources. To conserve species and ecosystems, Pakistan has a network of 225 Protected Areas, comprising 14 National Parks, 99 Wildlife Sanctuaries, 96 Game Reserves, and 16 unclassifieds (private, proposed or recommended) and a biosphere reserve and nine wetland sites of international importance as Ramsar 
sites. The total area covered by these categories is $9,170,121$ ha which is $10.4 \%$ of the total land area. Most major habitats are represented within Pakistan's Protected Area system. However, the size, distribution and management of these areas do not meet the needs of the ecosystems they are meant to safeguard.

There are a number of important gaps and needs relating to the management of protected areas in Pakistan which can be filled through coordinated efforts across many sectors of society.

\section{Legal Framework}

The Federal and Provincial Governments are the most important stakeholders, with the overall responsibility for providing an adequate policy and legal framework, enforcing regulations, building capacity and providing incentives and funds for the conservation of biodiversity. The policies and programmes of key federal ministries are crucial to the conservation and sustainable use of biological diversity.

With regard to the conservation of species, a serious weakness in the law is that it deals excessively with animal species and no provision is made for the protection of threatened and endangered plant species. The existing laws attempt to control the hunting of designated game animals, but most of these regulatory measures have proved difficult to enforce. Some rules have been framed under the existing laws to protect a few selected species (falcons, cranes); the need for introducing additional control measures for other key threatened species should also be examined.

Under the existing wildlife law in Pakistan, there are three categories of Protected Areas: National Parks, Wildlife Sanctuaries, and Game Reserves. Existing wildlife laws do not provide an adequate framework for management. The laws give authority for protected area management to the provincial wildlife departments, but give no authority to these departments over the management of adjacent areas. Consequently, development activities in areas adjacent to protected areas often conflict with biodiversity conservation.

The current thinking on Protected Area management is that, to be effective, the communities living alongside the area should have a hand in management and should derive some benefits from the area. None of the existing categories of protected areas make allowance for participatory management by communities. A draft Model Wildlife Law empowering local communities to participate in joint wildlife management with governments has been prepared and is currently under review by provincial governments.

The three categories of PAs used in Pakistan are too limited for contemporary needs. Most of the remaining unprotected areas of biodiversity significance are 
currently used and managed by local communities in one way or another. The best way to protect these areas will be through the establishment of collaborative management regimes. However, the existing wildlife legislation in Pakistan does not provide for a protected area category in which sustainable use and community involvement can take place.

For an effective legal framework for the implementation of the CBD and related conventions, existing legislation should be reviewed to identify deficiencies and other shortcomings in relation to biodiversity conservation in Pakistan and to clearly define the jurisdictional limits of different law enforcement agencies. Local government laws should be amended to provide for greater community level participation in activities supporting biodiversity. The laws relating to communal ownership and access to biological resources should be reviewed and revised so as to protect and encourage customary natural resource management systems.

\section{Management Plans and Policies}

The most protected areas in Pakistan lack comprehensive management plans, and where plans do exist, they are not fully implemented. There is also a tendency to regard management plans as blueprints rather than adaptive strategies requiring constant updating. In recent years, some efforts have been taken to redress this situation, and plans have been developed for the Margalla Hills National Park (Federal Territory) and Khunjerab National Park (Northern Areas). Management plans for the Kirthar National Park in Sindh and the Hazarganji Chiltan National Park in Balochistan are also being prepared.

Existing sectoral policies and plans in Pakistan most pertinent to the conservation and sustainable use of biodiversity are those relating to wildlife, forestry, fisheries and agriculture. At the federal level, the formulation and coordination of wildlife policies and plans have been, since 1974, the responsibility of the National Council for Conservation of Wildlife (NCCW). At the provincial level, wildlife policy and planning are the responsibility of the provincial wildlife departments and/or the Wildlife Management Boards, wherever they exist. Pakistan's existing wildlife policies and plans tend to place heavy emphasis on fauna to the exclusion of flora, and on game animals as opposed to non-game species. They relate almost exclusively to the establishment of protected areas, and trade controls for listed species. A new national Wildlife Policy has been drafted by GOP and circulated to the provinces for their comments. This policy is more comprehensive in that "wildlife" is defined to include all wild species and their habitats; however, it does not include domesticated fauna or flora, or genetic material.

The main planning instruments in Pakistan are the Perspective Plan, Five Year Plan and Annual Development Plan. Prior to Cabinet approval of the NCS in 1992 , these plans gave scant attention to environmental issues in general, and even 
less to biodiversity in particular. However, the influence of the NCS is clearly seen in the Eighth Five Year Plan (1993-1998), which identifies the environment as a 'critical issue'. Conservation of natural resources and protection of the environment are clearly identified as plan objectives. The plan prioritises the development of a coherent legislative framework, institutional strengthening, and the promotion of environmental awareness. Mention is made of the expansion and management of protected areas, ex-situ measures for plant conservation, and 'action' for the preservation of endangered species.

Some efforts are being made to develop understanding and mechanisms for making the management of protected areas more effective, as there is clear indication of certain gaps in the management capacity within the protected areas. As a followup exercise of two workshops which were earlier held in Bhutan (1999) and Bhopal, India (2000), a workshop was organized by the WWF and the World Bank on the effective management of protected areas with a view to creating awareness about the significance of management of protected areas and highlighting the role of performance indicators to measure the effectiveness of protected areas. Similar joint efforts can play a vital role in improving the use of information for the management of protected areas.

There is urgent need to adopt appropriate policies and plans that promote the conservation and sustainable use of biodiversity and integrate biodiversity conservation measures into sectoral plans and programmes; to expand Pakistan's protected area system to ensure representation of all terrestrial, freshwater, coastal, and marine ecological zones. Priority should be accorded to the critically threatened ecosystems, marine and coastal ecosystems, and other insufficiently represented ecological zones. Particular attention should also be accorded to expanding the protected area systems in Balochistan, NWFP, and southeastern Pakistan. There is a need to identify priority areas for international designation under the World Heritage Convention, the UNESCO Man and the Biosphere Programme, and the Ramsar Convention.

\section{Capacity Building}

The provincial wildlife departments lack the capacity to carry out their functions effectively, and in particular, suffer from a shortage of suitably trained personnel. A major thrust is required to buildup capacities of scientists, researchers, NGOs, decision-makers and planners through their participation in training programmes/ workshops/ training courses.

Protected areas including biosphere reserves, national parks, wildlife reserves, will prosper only if they are supported by the public, the private sector, and the full range of government agencies. Yet such support is unlikely, unless society appreciates the importance of protected areas to its own interests, and protected areas are well- 
managed and contribute to the national welfare in a cost-effective way. A crucial foundation for success is full cooperation between individuals and institutions.

A stronger partnership is required between managers of protected areas and other sectors of society. For this purpose, the current capacity and the biodiversityrelated training needs of natural resource managers, conservation professionals and other concerned staff should be assessed to initiate in-service training courses, to enhance existing training programmes in natural resource management, through the provision of funding, staff, and equipment and also to strengthen the capabilities of NGOs and community institutions to play an effective role in the conservation and management of biodiversity; in particular, initiate training programmes with "umbrella NGOs" which have large networks of community-based organisations.

\section{Community Involvement}

As direct users of biological diversity, local communities have an important role to play in resource conservation and use. The active involvement of communities in the management of wild species and ecosystems, where communities become the custodians and beneficiaries of biodiversity, may be the most promising approach to halt further loss of biodiversity in Pakistan.

At the local level, for example, communities often bear the ecological costs of unsustainable resource use practices carried out by external organisations, but receive few of the benefits. At the national level there is no pricing and valuation system for biodiversity; as a result, the government does not determine, and therefore does not charge for the real costs of biodiversity use.

It is generally recognized that activities which occur in areas adjacent to protected areas may be critical to the viability of the protected areas themselves. Adjacent communities ultimately control the protected area to the extent that if the local population is negatively affected by the protected area, then this area may be destined to fail. However, if local people are involved in the management of protected areas, and other forms of development, compatible with the goals of the protected area are promoted in adjacent areas, then the protected area's long-term viability is likely to be enhanced.

A new approach is clearly needed in which local people are no longer considered to be the problem but rather, part of the solution. A number of recent innovative projects (e.g. the UNDP/GEF funded project, "Maintaining Biodiversity with Rural Community Development") are now testing this approach in Pakistan. The results to date have been encouraging, and demonstrate that local communities can be effective custodians and managers of biological resources. This approach will be helpful in establishing new biosphere reserves (Palas Valley, the Indus Delta), 
improving the management of existing biosphere reserve (Lal Suhanra), and building more positive relationships with the people who live in or around protected areas.

\section{Disproportionate Distribution of Costs and Benefits}

Perhaps the most critical cause of biodiversity depletion in Pakistan is the disproportionate distribution of costs and benefits associated with the conservation and use of biological resources. Those who benefit from the exploitation of biodiversity do not bear the proportional costs of biodiversity depletion; rather, they pass on many costs to other segments of society which do not have an equal share in the benefits.

The appropriation of natural resources by the state, and the subsequent development of centralized structures have also deterred communities from taking an interest in the long-term sustainability of their natural resources. This has had detrimental effects on biodiversity conservation in Pakistan.

\section{Incentives and Disincentives}

The integrated use of incentives and disincentives is a particularly powerful means of promoting conservation and sustainable utilisation, and is being accorded increasing attention by many governments. Pakistan, however, has made relatively little use of this approach to date. Because the benefits of biodiversity are not widely understood or accounted for, very few incentives have been instituted to encourage conservation or sustainable use; similarly, appropriate disincentives are scarce and weakly enforced. "Perverse" incentives are also widespread, particularly in the agricultural sector; irrigation subsidies for example, encourage the wastage of water, and contribute to the degradation of freshwater and coastal ecosystems.

An integrated system of incentives and disincentives at the national and local levels to encourage the conservation and sustainable use of biodiversity must be introduced. These measures may include fiscal incentives such as tax exemptions or deductions for the conservation of particular habitats or species; tax reductions for the importation of equipment used in conservation programmes; and tax deductions for donations to conservation NGOs. Service-oriented incentives, designed to link community development programmes with the conservation of biodiversity, for example, communities living adjacent to protected areas could be accorded priority for public education programmes and technical assistance in agriculture, forestry and other fields, as well as social incentives, designed to improve the quality of life. These include measures such as clarification of land tenure and the creation of new institutions to manage biodiversity. 


\section{Education and Awareness}

Local communities rarely have any role to play in the management of protected areas in Pakistan. Few efforts have been directed at raising public education and awareness in areas adjacent to protected areas, providing environmentally sound and sustainable development assistance to local communities, or formulating appropriate packages of incentives and disincentives. Consequently, local communities either continue to disregard protected area provisions leading to degradation of the protected area, or where those provisions are enforced against local communities' interests, conflicts have arisen. The conflict between local communities and park authorities in the Khunjerab National Park, arising from the loss of grazing rights, is well known.

Pakistan has already developed an overall strategy for environmental education and awareness under the National Conservation Strategy; more detailed plans are contained in the provincial conservation strategies (e.g. SPCS, BCS, NACS). However, there is a need to ensure that the particular needs of biodiversity are not marginalized in a more general "greening" of public education and awareness.

\section{Research and Training}

Research institutions are responsible for documenting elements of biodiversity in Pakistan and for monitoring the health of ecosystems. Training institutions play an important role in building professional capacity in the fields of conservation and sustainable use. However, much is yet to be learned about biodiversity conservation and sustainable use. The study and management of the interactions between people and biological resources require training in both the social and biological sciences, and form the basis for the multi-disciplinary field of conservation biology.

There is a need to reinforce scientific research, monitoring, training and education in protected areas and biosphere reserves since conservation and the natural use of resources in these areas require a sound base in the natural and social sciences as well as humanities. This need is particularly acute in countries where biosphere reserves lack human and financial resources and should receive priority attention.

\section{Financial Resources}

In a developing country like Pakistan, the availability of funds is not easily ensurable for any conservation effort. To gather sufficient funds and support, the general public must be better sensitized to the rapid loss of biodiversity, and the need for its conservation. 
Finally, it should be emphasised that funds spent on biodiversity conservation and management are not unrecoverable expenditures; rather, they are investments in a country's future ecological, economic, and social security. Investments which will yield substantial benefits at virtually all levels and sectors of society. Present economic tools and measurements, such as the national income accounts, fail to recognise or accord a value to these benefits. Sincere efforts are required to seek increased bi-lateral and multi-lateral funding for biodiversity programmes.

\section{Mountain Protected Areas in Pakistan: The Case of the National Parks}

In the last 20 years, Pakistan has gazetted three northern mountain areas as national parks. Chitral Gol National Park, in Chitral District of the Northwest Frontier Province (NWFP), comprises the 7,750 ha watershed of the Chitral Gol immediately west of Chitral town. Khunjerab National Park, in Gilgit District of the Northern Areas, comprises $2,269 \mathrm{~km}^{2}$ in the Gojal tehsil on either side of the Karakoram Highway (KKH) from Dih to the Pakistan-China border at the Khunjerab Pass. The Central Karakoram National Park is mostly in the Skardu District of the Northern Areas, but also includes areas within the Gilgit District. The park's area has not been surveyed, but comprises the Baltoro, Panmah, Biafo and Hispar glaciers and their tributary glaciers. Each park has a separate history, but all share a fundamental gap between usage and control. This basic inequity underlies the unique problems of each national park. When ownership and usage are separate, there is a resulting lack of sufficient control over resources by either party. Until this conflict is resolved, effective management remains impossible.

With this increase in access, the mountain pastures, valleys, and wildlife habitats, previously valued for centuries as grasslands and woodlands, have now become the objects of desire of a number of competing interests - resort hotels, adventure tourism, big game hunting, mountaineering, conservation organizations, and the military, to name a few. Each group is interested in maximizing its return from usage of the area. The traditional usage of the villagers also figures into the equation. Each group of users tries to exert control over the areas, and each group has its own ideas as to how the areas should be managed. The relevant point for management is that effective management must take into account the needs of all user groups and develop strategies for cooperation between them. For example, in Pakistan, parks have largely been concerned with protection. Yet protected area managers throughout the developing world have realized that protected area management must be coupled with social and economic development, if biodiversity is to be conserved. This approach to management is only just beginning to find a foothold in Pakistan.

In addition, the rigid prescriptive structure of Pakistan's national parks precludes any direct role in planning and implementation for local people. The existing legislative basis for national parks excludes many types of usage. Pakistan's 
1975 national park legislation is similar to the 1978 definition formulated by IUCN - The World Conservation Union. Although the IUCN definition has since changed considerably to incorporate new thinking on park management, the Pakistan definition remains unchanged. The park structure presently in place in Pakistan actually amplifies conflict, as exemplified by the history of court cases in Chitral Gol and in Khunjerab. In Chitral, there is an ongoing 20-year history of litigation between the government and the ex-Mehtar of Chitral, Saiful Mulk Nasir. The ex-Mehtar claims Chitral Gol is his private property, whereas the government claims it is state property. Local people have now joined the lawsuit claiming their right to Chitral Gol. The case, as of June 1995, is still before the courts. In Khunjerab, the government attempted to ban traditional grazing, but failed to offer sufficient compensation to local communities. Villagers obtained a court order in October 1990 to permit them to continue grazing. But in 1991, the Khunjerab Security Force (KSF), a police organization, forcibly evicted them from the park. These lawsuits and police actions are symptomatic of the gap between usage and control, as well as of the distance between decision-makers in Pakistan's capital, Islamabad, and the actual protected areas.

Recent developments in Khunjerab may point to a way ahead. The management plan currently under review by the federal government follows an approach termed co-management. Co-management implies that all involved parties work together as equal partners in decision-making as well as in implementation. This requires the government to share power and responsibility for protected area management with local communities and other user groups. This approach holds forth the possibility of harmonizing the issue of usage and control. Co-management does not require authorities to give up or transfer legal jurisdiction, but it does demand that they equally share decision-making power with all other user groups, including local communities, and respect and enhance the rights, aspirations, knowledge, skills and resources of all user groups.

Of course, the burden also falls on the users. They can no longer simply be users, but must take responsibility for the results of their use, learn how to participate in the management of the area and how to work with other users.

The Central Karakoram National Park, established in late 1993, hopefully will not be plagued by the set of problems which have plagued Chitral Gol and Khunjerab. IUCN, a main proponent of the park, has declared that local people are at the heart of this park.

It seems unlikely that the exercise of government control over these mountain parks will resolve conflicts resulting from multiple users. It seems equally unlikely that the exercise of private control can resolve the conflicts, or bring to bear the needed resources and expertise to effectively manage these areas. Given the competing interests of today's multiple user groups, a traditional village-based 
common property regime is also impractical. Rather, a joining together of all user groups and individuals, together with the government, in a co-managed approach that links conservation with development appears to be the best approach for managing these areas today. The sad result of an unwillingness or inability to do so will be the loss of unique ecosystems and species - a loss for Pakistan and for the world. 